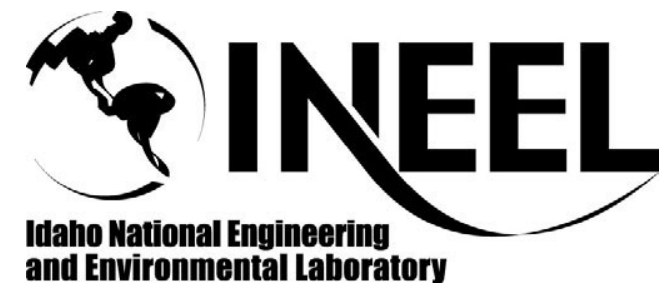

Idaho National Engineoring

and Environmental Laboratory
INEEL/CON-02-00644

PREPRINT

Full-Field Imaging Of Acoustic Motion At

Nanosecond Time And Micron Length Scales

Ken L. Telschow

Vance A. Deason

David L. Cottle

John D. Larson III

October 8, 2002

2002 IEEE International Ultrasonics Symposium

This is a preprint of a paper intended for publication in a journal or proceedings. Since changes may be made before publication, this preprint should not be cited or reproduced without permission of the author.

This document was prepared as a account of work sponsored by an agency of the United States Government. Neither the United States Government nor any agency thereof, or any of their employees, makes any warranty, expressed or implied, or assumes any legal liability or responsibility for any third party's use, or the results of such use, of any information, apparatus, product or process disclosed in this report, or represents that its use by such third party would not infringe privately owned rights. The views expressed in this paper are not necessarily those of the U.S. Government or the sponsoring agency. 


\title{
Full-field Imaging of Acoustic Motion at Nanosecond Time and Micron Length Scales
}

\author{
Ken L. Telschow*, Vance A. Deason and David L. Cottle \\ Idaho National Engineering and Environmental Laboratory \\ Idaho Falls, ID 83415-2209, USA \\ John D. Larson III † \\ Agilent Technology Laboratories \\ 3500 Deer Creek Road, Mail Stop 26M-2 \\ Palo Alto, CA 94304-1392, USA
}

\begin{abstract}
A full-field view laser ultrasonic imaging method has been developed that measures acoustic motion at a surface without scanning. Images are recorded at normal video frame rates by employing dynamic holography using photorefractive interferometric detection. By extending the approach to ultra high frequencies, an acoustic microscope has been developed capable of operation on the nanosecond time and micron length scales. Both acoustic amplitude and phase are recorded allowing full calibration and determination of phases to within a single arbitrary constant. Results are presented of measurements at frequencies at $800-900 \mathrm{MHz}$ illustrating a multitude of normal mode behavior in electrically driven thin film acoustic resonators. Coupled with microwave electrical impedance measurements, this imaging mode provides an exceptionally fast method for evaluation of electric to acoustic coupling and performance of these devices. Images of $256 \times 240$ pixels are recorded at $18 \mathrm{~Hz}$ rates synchronized to obtain both in-phase and quadrature detection of the acoustic motion. Simple averaging provides sensitivity to the subnanometer level calibrated over the image using interferometry. Identification of specific acoustic modes and their relationship to electrical impedance characteristics show the advantages and overall high speed of the technique.
\end{abstract}

\section{INTRODUCTION}

Ultrasonic resonators are being developed for specialized signal processing by the telecommunication industry. Operation is now being performed at ultra high frequencies (UHF) and higher frequencies are contemplated for the future. Very small dimensions are needed to achieve these ultra high frequencies as well as satisfy other telecommunication requirements. In order to optimize the development, operation, and manufacture of these resonators, direct measurements of the resulting acoustic motion has proved very helpful. Previous measurements of this type using interferometric single-point techniques employed scanning to create images of the surface motion. [1,2,3,4]. This paper describes an optical full-field method for imaging surface acoustic motion that offers significant improvement in speed over the scanning method.

\section{DYNAMIC HOLOGRAPHIC DETECTION}

Our approach is to perform optical detection of ultrasonic motion in a microscopic geometry using photorefractive holography $[5,6]$. The apparatus and operation of this approach have been previously described for measuring UHF acoustical motion at a single point [4]. In this paper we describe results from that setup modified to record images of the surface. These images are processed in the photorefractive crystal to record images of the surface displacement at synchronized acoustic phase intervals with a video camera. With the imaging implementation of the photorefractive technique, scanning is no longer necessary to measure large areas in very short times, as will be described. Operation at any frequency is achieved by tuning an electro-optic modulator to that frequency offset by $1 / 4$ of the imaging capture frequency of the video camera. A sequence of 4 images phase shifted by $90^{\circ}$ are recorded at a rate of $4.5 \mathrm{~Hz}$ (video camera running at $18 \mathrm{~Hz}$ ). Images are 
subtracted from their $180^{\circ}$ counterparts to produce both the in-phase and quadrature images of the acoustic motion. From these images the resultant motion at any time during the vibration period can be readily calculated producing very enlightening movies of the acoustic displacement vibration. Complete data acquisition at one frequency of 256x240 pixel images (61440 spatial points) with 128 averages are achieved in less than 30 seconds. This equates to a data acquisition speed of over $275 \mathrm{~K}$ points/sec with a minimum detectable displacement of about $0.1 \mathrm{~nm}$. Previous reports achieved data acquisition speeds of 8-9 points/sec with detectability of $0.0003 \mathrm{~nm} \mathrm{[2]} \mathrm{and} 487$ points/sec with detectability of $0.01 \mathrm{~nm}$ [3].

\section{FILM BULK ACOUSTIC RESONATOR}

The FBAR resonator is a micromachined membrane of Aluminum Nitride (AlN) with acoustically thin refractory metal electrodes, designed to resonate at $\sim 900 \mathrm{MHz}$. It is grown on a silicon wafer for support at the edges. An image of the nearly square $160 \mu \mathrm{m} \mathrm{FBAR} \mathrm{is} \mathrm{shown} \mathrm{in} \mathrm{figure} \mathrm{1,} \mathrm{as}$ recorded by the data acquisition video camera. Horizontal interference fringes are seen caused by an integral beamsplitter within the microscope. Although undesirable (and to be eliminated in future designs), the beamsplitter artifacts cause only minor difficulty in interpreting the acoustic motion images shown later.

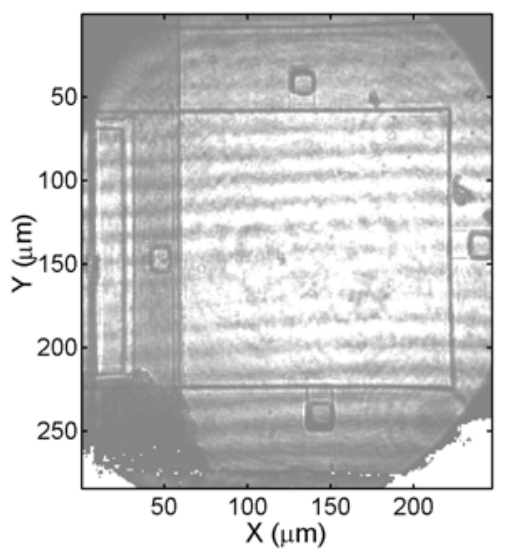

Figure 1: Thin Film Bulk Acoustic Resonator

In operation, the FBAR vibrates primarily in the plate thickness mode, but also exhibits many lateral mode motions at nearby frequencies. It presents a highly reactive load to the driver amplifier. Figure 2 illustrates the magnitude of impedance vs. frequency for the FBAR studied.

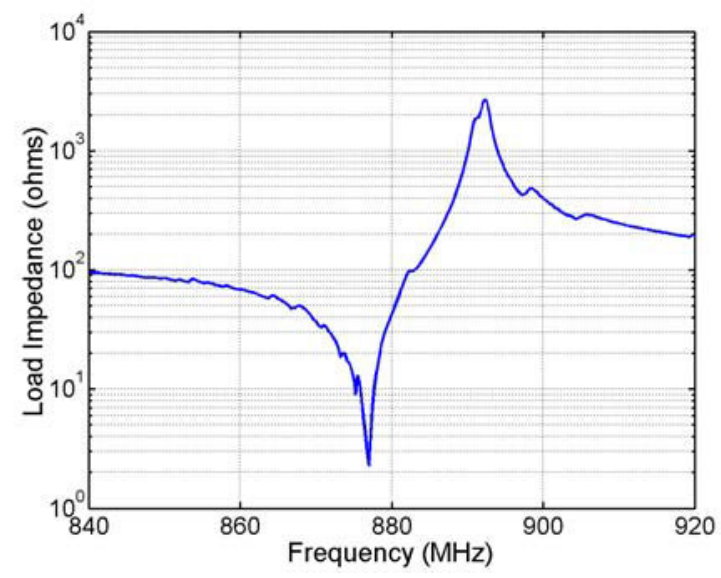

Figure 2: Measured Electrical Input Impedance Magnitude of the FBAR Resonator.

\section{IMAGING MEASUREMENTS}

Images of the normal acoustic displacement were recorded at frequencies around the first thickness resonance at $878 \mathrm{MHz}$. Figure 3 shows the motion well below this resonance where many lateral modes can be seen. The first image at $840 \mathrm{MHz}$ shows lateral mode wavelengths of around $4 \mu \mathrm{m}$, which are near the resolution of the optical microscope with the $20 \mathrm{X}$ objective used. The mode structure changes quickly as the frequency is increased toward resonance. Complicated mode combinations are seen that increase in wavelength to values approaching the plate dimensions. Figure 4 shows the mode structure at the last few $\mathrm{MHz}$ below and at the series resonance. Very near the series resonance, a single "bull's eye" mode is seen that can reach very high peak amplitudes. Relative amplitudes of all the modes are roughly characterized in the figures by using the same scale for the intensity plotted for all the modes.

Above the series resonance, see figure 5, the acoustic motion develops more and more completely into the main thickness breathing motion over the entire surface area of the plate. However, here again a multitude of very short wavelength lateral modes are seen that decrease in wavelength as the frequency is increased. As all the images are recorded in both inphase and quadrature form, the complete acoustic motion in both amplitude and phase is known at all points in the image at any time during the motion. 

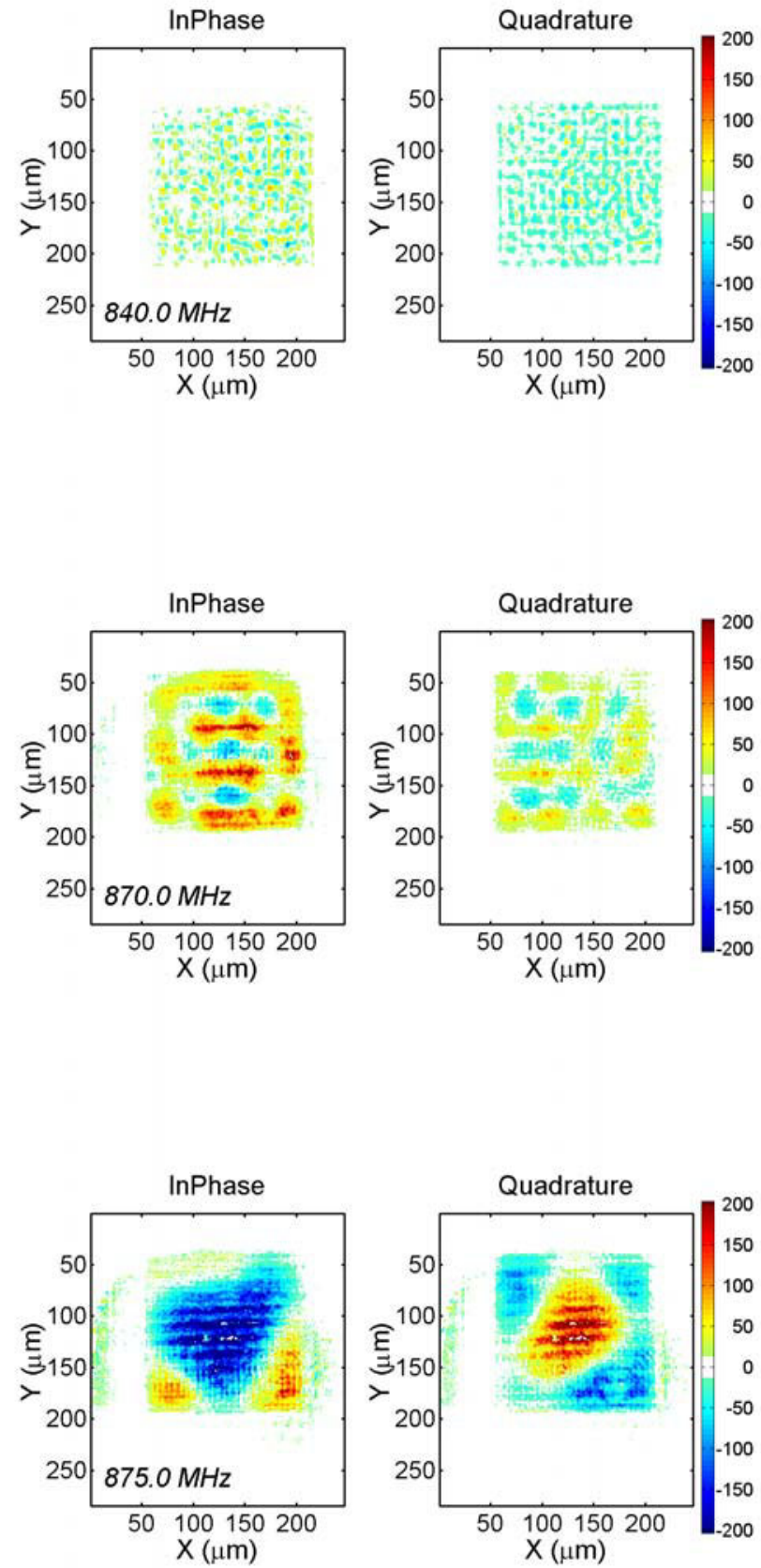

Figure 3: Acoustic normal displacement amplitude images below the primary resonance.

This allows one to advance the phase analytically to simulate motion at the operating frequency. Movies made from this process are very useful for observing mode behavior and particularly, the
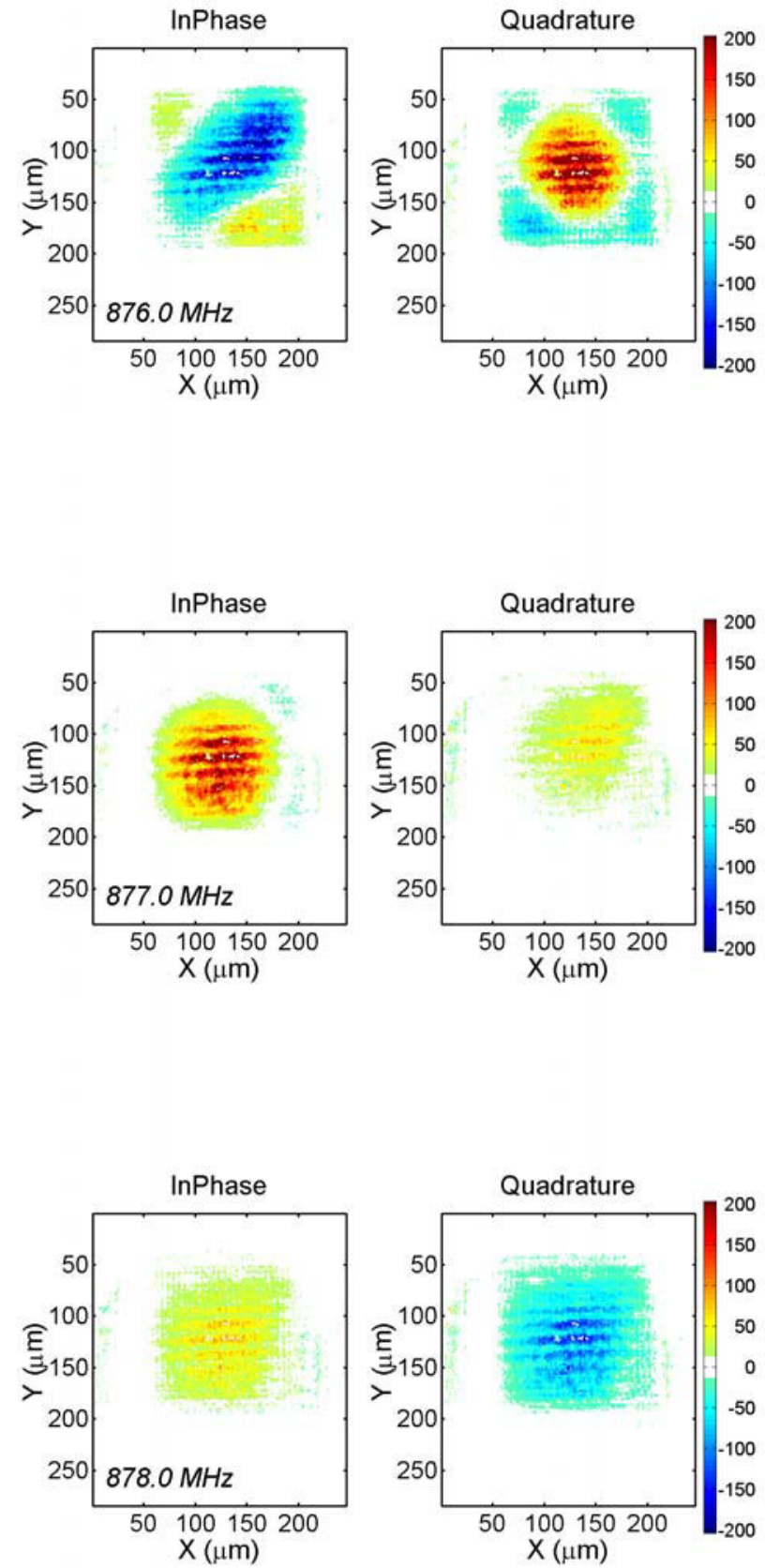

Figure 4 Acoustic normal displacement amplitude images near the primary resonance.

relative motion of the various modes that are simultaneously excited. All the images shown are with an initial phase of zero. The region around zero displacement is artificially made white in the images. 

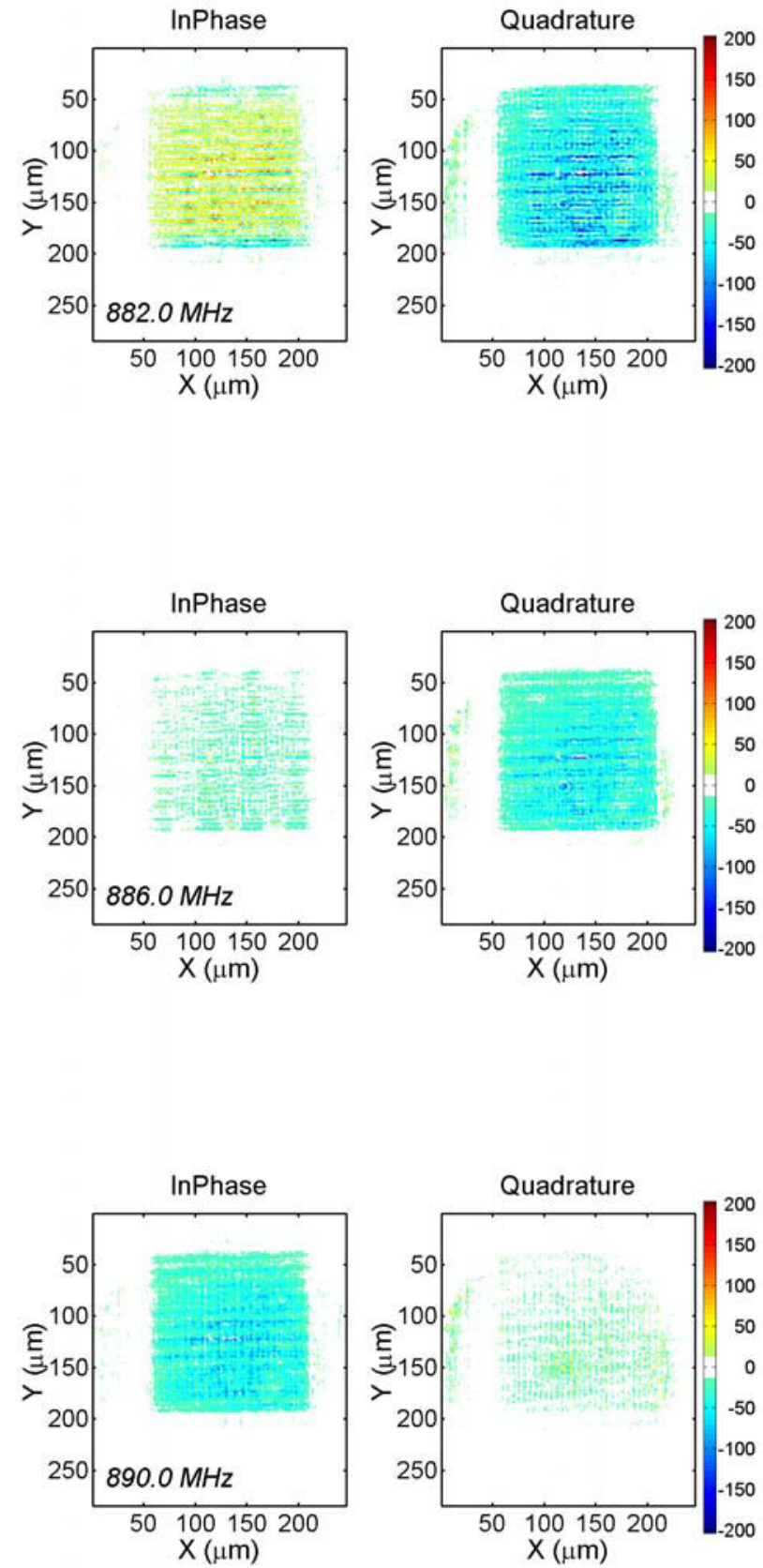

Figure 5: Acoustic normal displacement amplitude images above the primary resonance.

\section{CONCLUSION}

A full-field imaging method has been presented that rapidly measures the acoustic amplitude and phase over the entire surface simultaneously. Detailed knowledge of the acoustic amplitude and phase at ultra high frequencies can be readily obtained. The full-field nature of the method provides very high speed data acquisition rates of over $275 \mathrm{~K}$ points/sec. The method is operable at virtually any frequency with the same subnanometer sensitivity. Images obtained at near $\mathrm{GHz}$ frequencies allow operation on nanosecond time scales. Microscopic imaging provides resolution in the micron range, limited by the optical objective used.

\section{ACKNOWLEDGEMENTS}

This work was sponsored by the U.S. Department of Energy, Office Basic Energy Sciences, Materials and Engineering Physics under DOE Idaho Operations Office Contract DE-AC07-99ID13727 and Agilent Technologies Inc

1 J. V. Knuutila, P. T. Tikka and M. M. Salomaa, "Scanning Michelson interferometer for imaging surface acoustic wave fields," Opt. Lett. 25, 613 (2000).

2 J. E. Graebner, B. P. Barber, P. L. Gammel, D. S. Greywall and S. Gopani, "Dynamic visualization of subangstrom high-frequency surface vibrations," Appl. Phys. Lett. 78, 159-161 (2001).

${ }^{3}$ G. G. Fattinger and P. T. Tikka, "Modified MachZender laser interferometer for probing bulk acoustic waves," Appl. Phys. Lett. 79, 290-292 (2001).

${ }^{4}$ Ken L. Telschow, Vance A. Deason, David L. Cottle and John D. Larson III, "UHF Acoustic Microscopic Imaging of Resonator Motion" 2000 IEEE Ultrasonics Symposium Proceedings, S.C. Schneider, M. Levy, B. R. McAvoy eds., IEEE, Piscataway, NJ. Vol.1, 631-634 (2000).

${ }^{5}$ K.L. Telschow, V. A. Deason, R. S. Schley and S. M. Watson, "Direct Imaging of Lamb Waves in Plates using Photorefractive Dynamic Holography," J.Acoust. Soc. Am. 106(5), 2578-2587 (1999).

${ }^{6}$ K. L. Telschow and V. A. Deason, "Imaging Laser Ultrasonics Measurement of the Elastodynamic Properties of Paper," 2001 IEEE Ultrasonics Symposium Proceedings, G. A. Schneider, D. E. Yuhas eds., IEEE, Piscataway, NJ. Vol.1, 737-745 (2001).

* Ken Telschow: telsch@inel.gov

† John Larson: john_larson@agilent.com 